\title{
Reflexões sobre o legado colonial português na regulação das práticas sexuais entre pessoas do mesmo sexo em Moçambique
}

Reflections on the Portuguese colonial legacy in the regulation of same-sex sexual practices in Mozambique

\section{Gustavo Gomes da Costa}

\section{(2) OpenEdition Journals}

\section{Edição electrónica}

URL: https://journals.openedition.org/aa/8325

DOI: $10.4000 / a a .8325$

ISSN: 2357-738X

\section{Editora}

Programa de Pós-Graduação em Antropologia Social (UnB)

\section{Edição impressa}

Paginação: 152-170

ISSN: 0102-4302

\section{Refêrencia eletrónica}

Gustavo Gomes da Costa, «Reflexões sobre o legado colonial português na regulação das práticas sexuais entre pessoas do mesmo sexo em Moçambique», Anuário Antropológico [Online], v.46 n.2 | 2021, posto online no dia 30 maio 2021, consultado o 21 setembro 2021. URL: http:// journals.openedition.org/aa/8325 ; DOI: https://doi.org/10.4000/aa.8325

\section{(c) (i) (9)}

Anuário Antropológico is licensed under a Creative Commons Atribuição-Uso Não-Comercial-Proibição de realização de Obras Derivadas 4.0 International. 


\title{
anuário antropológico \\ v. $46 \cdot \mathrm{n}^{\circ} 2 \cdot \mathrm{majo-agosto} \cdot 2 \odot 21.2$
}

\section{Reflexões sobre o legado colonial português na regulação das práticas sexuais entre pessoas do mesmo sexo em Moçambique}

\author{
Reflections on the Portuguese colonial legacy in the regulation of same-sex sexual \\ practices in Mozambique \\ DOI: https://doi.org/10.4000/aa.8325
}

\begin{abstract}
Gustavo Gomes da Costa
Universidade Federal de Pernambuco, Centro de Filosofia e Ciências Humanas, Departamento de Sociologia, Recife, PE, Brasil

Professor adjunto de Sociologia da UFPE e pesquisador dos programas de pós-graduação em sociologia e direitos humanos na mesma instituição. É pesquisador afiliado da Universidade de Glasgow (Reino Unido) e pós-doutor pela Université Libre de Bruxelles (Bélgica).
\end{abstract}

Nas últimas décadas, tem se observado na África Subsaariana, aumento expressivo da perseguição à população de lésbicas, gays, bissexuais, travestis e transexuais (LGBT). Essa perseguição tem ocorrido em países que herdaram das suas antigas metrópoles, legislações punitivas das práticas homoeróticas. $O$ colonialismo britânico foi aquele que mais se engajou na punição das práticas sexuais entre pessoas do mesmo sexo, legando ampla legislação nos arcabouços jurídicos de suas ex-colônias. Em relação ao colonialismo português, são poucos os estudos que se debruçam sobre a regulação das relações entre pessoas do mesmo sexo. 0 presente artigo propõe analisar os possíveis impactos do colonialismo português na regulação das sexualidades entre pessoas do mesmo sexo em Moçambique. Para tanto, o artigo analisou o processo de criminalização das práticas homoeróticas em Portugal e suas colônias africanas, e refletindo sobre os impactos da scientia sexualis lusitana no desenho da legislação contrária aos "vícios contra a natureza". 0 artigo também identificou a existência e aplicabilidade de leis específicas regulando a homossexualidade direcionadas à população nativa africana, assim como analisou o impacto de outros atores (p. ex., missionários religiosos) na regulação das relações sexuais entre pessoas do mesmo sexo em Moçambique.

Colonialismo. Homossexualidade. Moçambique. Legislação. Homofobia.
In the last decades, sub-Saharan Africa has witnessed a significant increase in the persecution of the lesbian, gay, bisexual, and trans (LGBT) population. This persecution has occurred in countries that have inherited punitive legislation for homoerotic practices from their former metropolises. British colonialism was the one that most engaged in the punishment of same-sex sexual practices, leaving ample legislation in the legal frameworks of its former colonies. Concerning to Portuguese colonialism, few studies focus on the regulation of same-sex sexual relations. The present article aims to analyze the possible impacts of Portuguese colonialism on the regulation of same-sex sexualities in Mozambique. For this purpose, the article analyzed the criminalization process of homoerotic practices in Portugal and its African colonies and discussed the impacts of Portuguese scientia sexualis on the design of legislation against the "vices against nature". The article also identified the existence and applicability of specific laws concerning same-sex sexuality directed toward the native African population, as well as it analyzed the impact of other actors (e.g., religious missionaries) on the regulation of same-sex sexual relations in Mozambique.

Colonialism. Homosexuality. Mozambique. Legislation. Homophobia. 


\section{Introdução}

Nas últimas décadas, a luta por direitos de lésbicas, gays, bissexuais, travestis e transexuais (LGBT) tem se expandido para os países do chamado "Sul Global". Em muitos desses países, as expressões da sexualidade não conformes com a heterossexualidade ainda são vistas como tabu e são alvo de intensa condenação moral e repressão política. Sessenta e oito Estados ainda condenam as práticas sexuais entre pessoas do mesmo sexo, sendo que 8 destes países preveem a pena de morte para os adeptos dessas práticas (ILGA World, 2019). No continente africano, particularmente na África Subsaariana, tem se observado aumento expressivo da homofobia, principalmente oriunda das instituições políticas. Em sua maioria, os países da região herdaram, das suas antigas metrópoles, legislações punitivas das práticas entre pessoas do mesmo sexo. Em muitos deles (Nigéria, Uganda e Zimbábue), líderes políticos têm proposto mudanças na legislação vigente, com vistas a aumentar a punição para aqueles adeptos da "sodomia" e de práticas sexuais supostamente contrárias "à ordem da natureza”. O caso que mais ganhou visibilidade na opinião pública internacional foi o de Uganda, onde o Parlamento chegou a aprovar em 2014 uma lei anti-homossexualidade ${ }^{1}$ que previa até a prisão perpétua para indivíduos portadores do vírus HIV que mantivessem relações sexuais com pessoas do mesmo sexo. Essa iniciativa teve ampla condenação internacional, uma vez que, como resultado de intenso trabalho de militância LGBT institucional (advocacy) nas instâncias internacionais, os direitos da população LGBT passaram a ser interpretados como direitos humanos, viabilizando sua tutela internacional (Lennox; Waites, 2016).

Contrastando com o atual cenário de recrudescimento da homofobia estatal está Moçambique, país da África Austral, onde se tem observado certo avanço da agenda legal/jurídica dos direitos da população LGBT em África. O país foi, junto com a África do Sul e Seychelles, uma das primeiras nações africanas a proibir a discriminação baseada na orientação sexual no mercado de trabalho em 2007 (Lennox; Waites, 2016). Recentemente, na contramão de outras nações africanas, Moçambique revisou seu código penal em 2015, retirando as menções aos "vícios contra a natureza” que viabilizavam a criminalização das práticas sexuais entre pessoas do mesmo sexo (Smith, 2015).

O colonialismo europeu tem sido apontado pela literatura especializada (Epprecht, 2013; Phillips, 2009; Murray; Roscoe, 2001; Human Rights Watch, 2008) como central para explicar o processo de recrudescimento da homofobia estatal, uma vez que a implementação das leis antissodomia na região foi resultado da ação do colonizador europeu, assim como a disseminação do mito da suposta "inexistência" da homossexualidade na África subsaariana. O colonialismo britânico foi aquele que mais se engajou na punição das práticas sexuais entre pessoas do mesmo sexo, haja vista a ampla legislação legada nos arcabouços jurídicos de suas ex-colônias. É provável que por essa razão, a quase totalidade dos estudos acadêmicos existentes tenha se debruçado nas ex-colônias britânicas. Em relação ao colonialismo português, são poucos os estudos que se debruçaram sobre a
1 A lei foi, posteriormente, declarada inconstitucional pela Corte Constitucional do país por vícios de tramitação (BBC News, 2014). 
regulação das relações entre pessoas do mesmo sexo nos territórios sob sua soberania (Figari, 2009; Miguel, 2014 e 2019; Mott, 2005; Vainfas, 2010). Embora os códigos penais das ex-colônias portuguesas na África tenham herdado a punição ao chamado "vício contra a natureza", previsão legal utilizada em Portugal desde 1912 para punir práticas homoeróticas (Cascais, 2016), é intrigante observar que nas ex-colônias portuguesas a perseguição contra lésbicas e gays não têm tido a centralidade que tem nas ex-colônias britânicas. O que se observa é um cenário de maior tolerância, em comparação com outros países africanos. Em enquete realizada pelo Africa Barometer em 33 países africanos (Dulani; Sambo; Dionne, 2016), identificou-se que as três ex-colônias portuguesas incluídas na pesquisa (Cabo Verde, Moçambique e São Tomé e Príncipe) ocupam posição de destaque no ranking de tolerância à homossexualidade, com 74\%, 56\% e 46\% dos entrevistados respectivamente declarando "aceitar" ou "não se importar" em ter um(a) vizinho(a) homossexual. Esse dado parece indicar a centralidade do legado colonial para compreender as razões para a perseguição atual de cunho homofóbico no continente.

O presente texto propõe analisar os possíveis impactos do legado do colonialismo português na regulação das sexualidades entre pessoas do mesmo sexo em Moçambique. Para isso, foram estabelecidos alguns objetivos específicos: a) analisar o processo de criminalização das práticas homoeróticas em Portugal e a sua extensão ao âmbito das colônias africanas; b) refletir sobre os possíveis impactos da reflexão promovida pelos acadêmicos da scientia sexualis lusitana no desenho da legislação contrária aos "vícios contra a natureza"; c) identificar a existência de leis específicas direcionadas à população nativa africana e sua aplicabilidade e d) analisar o impacto de outros atores (p. ex., missionários vinculados à Igreja Católica) na regulação das relações sexuais entre pessoas do mesmo sexo em Moçambique.

O estudo baseou-se em pesquisa documental, a partir da coleta de fontes primárias e secundárias no Arquivo Histórico Ultramarino e na Biblioteca Nacional de Portugal, ambos localizados em Lisboa. O texto é parte da pesquisa intitulada "Direitos humanos de lésbicas, gays, bissexuais e transexuais em Moçambique: limites e possibilidades da promoção da livre orientação sexual e identidade de gênero no contexto africano", desenvolvida junto ao programa de pós-graduação em sociologia da UFPE e à School of Social and Political Sciences da Universidade de Glasgow (Reino Unido), em parceria com o professor Matthew Waites.

$\mathrm{O}$ texto tem como referencial teórico as discussões propostas por autores alinhados ao paradigma pós-colonial, particularmente a obra de Anne McClintock (2010), que sustenta não ser possível compreender o colonialismo europeu (e a lógica de poder subjacente a ela) sem levar em conta a importância das dimensões de gênero e sexualidade. Para ela, "a dinâmica do gênero foi, desde o início, fundamental para assegurar e manter o empreendimento imperial" (McClintock, 2010, p. 23). A "obsessão vitoriana" em controlar a sexualidade das classes trabalhadoras e das populações colonizadas, de forma a criar uma mão de obra "dócil", "focada no trabalho" e racialmente "saudável" resultou na emergência de um in- 
tricado complexo de leis, normativas e regulamentos que proibiam uma miríade de comportamentos e práticas sexuais não procriativas (nomeadas de sodomia ou "atos contra a natureza") ou práticas sexuais que colocavam em xeque a pureza racial (a exemplo do intercurso sexual entre pessoas de raças distintas). Essas leis e regulamentos foram impostas às sociedades africanas, convertendo-as em laboratórios de experimentação legal das administrações coloniais (Human Rights Watch, 2008). Semelhantemente, Robert Aldrich (2003) explorou as relações entre o colonialismo e as sexualidades homoeróticas, especialmente a tensão entre as missões morais das ideologias imperialistas europeias, e como, na prática, o colonialismo fornecia rotas àqueles adeptos das sexualidades dissidentes do modelo heterossexual para disfrutar de novas experiências sexuais.

\section{0 colonialismo português em Moçambique}

A presença portuguesa na África remonta ao século XV, quando os navegantes fundaram entrepostos comerciais (conhecidos como feitorias) ao longo das costas oeste e leste. Eles foram a base do comércio de escravos e especiarias com as populações locais, bem como para a ocupação portuguesa na África. Até meados do século XIX, a presença portuguesa na África estava restrita a alguns portos ao longo das costas oeste e leste da África. A conferência de Berlim em 1885 e a possibilidade de Portugal perder territórios para outras potências europeias na "Partilha pela África" operou como um incentivo para o estado português aumentar sua presença administrativa e militar na África. Expedições militares e científicas foram lançadas para obter o controle efetivo das colônias, encontrando a forte resistência das populações locais. Somente depois de assegurar o controle militar dos territórios, em princípios do século XX, Portugal viabilizou a colonização e a sua soberania em Moçambique (Dias, 2007, p. 86).

O esforço para colonizar territórios em África ocorreu num contexto em que o Estado Português sofria de instabilidade política e problemas econômicos crônicos. Esta instabilidade, juntamente com uma economia de base agrária que não possuía os capitais necessários para dinamizar os esforços coloniais, forçou Portugal a delegar a companhias concessionárias estrangeiras (organizadas por capitais alemães, franceses e britânicos) não apenas os esforços para o desenvolvimento econômico, mas principalmente para o controle de seus territórios. A estas companhias, Lisboa concedeu direitos para explorar economicamente grandes áreas em troca de parte das receitas. Para algumas delas, como a Companhia de Diamantes de Angola (DIAMANG), o governo português concedeu funções quase governamentais, transformando-as em uma espécie de "enclaves autônomos" (Newitt, 1981, p. 77). As Companhias de Moçambique e Niassa controlaram quase metade do atual território moçambicano até 1941, quando Portugal assumiu o controle direto de todo o território (Pereira, 2001).

Uma característica específica da administração colonial portuguesa foi a tendência a considerar as suas possessões como parte integrante do território português. Apesar das diferenças na nomenclatura ("conquistas", "colônias", "domínios" 
ou "províncias ultramarinas"), os territórios portugueses na África legalmente não gozavam de muita autonomia política e administrativa de Lisboa (Oliveira, 2014). As ações administrativas coloniais locais tinham que seguir estritamente as diretivas do governo central e quase todas as leis eram elaboradas em Lisboa. Cada colônia tinha um governador responsável por executar e adaptar as diretrizes de Lisboa às condições locais, tendo amplos poderes, de legislar sobre os chamados "assuntos indígenas". Em 1951, como resposta à pressão internacional pela descolonização, a administração do Estado Novo (1933-1975) renomeou o Departamento como Departamento do Ultramar para reforçar a ideia de que os territórios ultramarinos eram parte integrante do território português continental (Abshire; Samuels, 1969).

De acordo com a Lei Orgânica do Ultramar de 1963, a menor unidade administrativa das províncias ultramarinas era o conselho, responsável pela arrecadação de impostos e recrutamento de mão de obra (Abshire; Samuels, 1969). Devido à falta de recursos, os administradores coloniais dependiam de chefes locais (régulos) recrutados pelos poderes coloniais para garantir o controle das populações nativas. A este respeito, os territórios portugueses experimentaram alguma autonomia administrativa "de fato" antes e depois de 1963, resultando em algo semelhante ao modelo britânico de indirect rule, em que a lei portuguesa coexistiria com os "usos e costumes" nativos. Essa característica da colonização portuguesa foi enfatizada como uma demonstração de um colonialismo supostamente benigno, apresentado como não impondo a lei e a tradição europeias, fundindo-as com os costumes locais, numa espécie de governo igualitário.

No entanto, um olhar mais atento às ideias e abordagens implementadas pela burocracia colonial portuguesa demonstra claramente que não era esse o caso. Tal como seus homólogos britânicos e franceses, os oficiais coloniais portugueses consideravam a população nativa como racialmente inferior e os "usos e costumes" indígenas como primitivos e, por vezes, bárbaros (Newitt, 1981; Zamparoni, 2012). O Estatuto Político, Civil e Penal Indígena de 1929 estabelecia discriminações legais baseadas na raça nos territórios ultramarinos portugueses, classificando como indígenas todos os indivíduos "da raça negra ou seus descendentes que, por sua ilustração e costumes, se não distingam do comum daquela raça" (Artigo $2^{\circ}$ ). O Ato Colonial de 1930 foi além e estabeleceu a necessidade de "estatutos especiais dos indígenas", de acordo com o "estado de evolução dos povos nativos" (Artigo 22\%).

Estes estatutos combinavam o direito privado e público português com usos e costumes individuais, domésticos e sociais [indígenas], na medida em que não fossem incompatíveis com a "moral e ditames da humanidade". Ambos os decretos indicavam que a população "nativa" estava em um estado primitivo de evolução e que a lei indígena estava em uma posição inferior em comparação à lei europeia (Macagno, 2020). Essa só era aplicada aos cidadãos brancos e aos "assimilados", status concedido àqueles africanos capazes de falar e escrever fluentemente a língua portuguesa e que estivessem regularmente empregados (Hall; Young, 1997). Com o progresso da colonização, os "uso e costumes" indígenas deveriam ser “assimilados” pela lei portuguesa (Pereira, 2001). Isto é confirmado por Serra ao 
analisar a importância do "uso e costumes" na administração colonial portuguesa em Moçambique, quando afirma:

Portugal precisou efectivamente de contar com as instâncias e direitos locais, pelo menos enquanto não reunisse as condições humanas, materiais e financeiras necessárias à padronização política, económica, social, cultural e religiosa do império colonial português (Serra, 2010, p. 9).

Assim, de acordo com sua análise, a incorporação dos usos e costumes indígena na legislação colonial não seria um exemplo de "pluralismo legal”, mas uma consequência de uma abordagem pragmática da colonização, que dependia de acordos complexos e às vezes frágeis com autoridades indígenas para garantir o controle dos territórios. A assimilação dos "usos e costumes" indígenas pelas autoridades coloniais enfrentou algumas resistências, especialmente de missionários católicos, que viram algumas tradições indígenas como bárbaras e não-cristãs. Voltaremos a este tópico a seguir.

\section{Regulação e criminalização das sexualidades no mesmo sexo em Portugal e suas colônias}

Seguindo o princípio de integridade entre Portugal e os seus territórios ultramarinos, os direitos civil e penal continental eram, em teoria, aplicáveis a todos os cidadãos dentro do império, independentemente das suas origens. Nesse sentido, para compreender a regulação das sexualidades do mesmo sexo nas colônias portuguesas, é preciso olhar para como a questão foi tratada no território continental. Até 1821, a sodomia foi criminalizada em Portugal e nos seus territórios ultramarinos ao abrigo da lei canônica que punia o "pecado nefasto" com a pena de morte (Mott, 2005). Inspirada no código napoleônico, a legislação penal portuguesa, após 1821, ignorou as práticas sexuais entre pessoas do mesmo sexo, excluindo a sodomia do rol de crimes previstos. Essa exclusão não significou que a homossexualidade tenha sido legalizada, já que os homossexuais continuavam a ser alvo de frequentes batidas policiais em locais públicos (como parques, estações de trem e banheiros públicos), sob a provisão que criminalizava o "atentado ao pudor" (Cascais, 2016).

No entanto, o Código Penal de 1852 (e sua versão revisada de 1886), no artigo 391, alínea 2, equiparou o "atentado ao pudor" com estupro e agressão sexual, condicionando sua punição ao uso de coerção ou violência. Isso sugeria que a homossexualidade consensual, em si, não seria mais criminalizada, apesar do contínuo assédio policial. Isto mudou drasticamente em 1912, quando o Parlamento Português aprovou uma nova legislação que criminalizou, juntamente com mendicância e vadiagem, aqueles que "se entregassem à prática do vício contra a natureza”. A lei previa que indivíduos enquadrados como vadios estariam sujeitos à prisão de um mês a um ano e, em caso de recorrência, ao degredo para as colônias e/ou até 6 anos de internação em um estabelecimento penal. A lei estava 
fundamentada em um entendimento moderno da homossexualidade, em que o homossexual como indivíduo (e não a relação sexual entre pessoas do mesmo sexo) era o objeto da repressão legal (Cascais, 2016). A equivalência entre homossexualidade e vadiagem exprimia as ansiedades da sociedade portuguesa em processo de urbanização, em que a ociosidade era percebida como uma ameaça social (Bastos, 1997).

A lei de 1912 não foi imediatamente estendida às colônias. De acordo com a legislação portuguesa, um decreto especial precisava ser emitido para que uma lei ordinária fosse aplicada nas províncias ultramarinas. Em 1929, uma versão mais curta da Lei de Vadiagem Metropolitana foi emitida como decreto válido em Angola e São Tomé e Príncipe. Embora os sujeitos de regulação judicial fossem os mesmos que em Portugal, as penas eram diferentes. Em Portugal, existiam penalidades e níveis de punição diferentes dependendo dos infratores e sua recorrência no delito, que ia de prisão ao degredo e à internação. No caso do Decreto de 1929, a única punição era o recrutamento para o trabalho forçado em qualquer um dos territórios coloniais portugueses. Aparentemente, isso indicava que o objetivo da legislação era fornecer mão de obra indígena particularmente às plantações de café e cacau em São Tomé e não necessariamente reprimir o "vício contra a natureza". Nenhum documento foi encontrado nos arquivos de Lisboa de qualquer indivíduo condenado a trabalhos forçados com base no "vício contra a natureza" fornecido pelo decreto de 1929.

No caso de Moçambique, um decreto de 1913 aplicável a Lourenço Marques (atual Maputo) permitiu que as autoridades locais obrigassem os indígenas a trabalhar com base nos crimes de vadiagem, alcoolismo, roubo e atentado ao pudor. No entanto, também não há registro de indivíduos envolvidos em práticas sexuais entre mesmo sexo condenados a trabalhos forçados com base na previsão contrária ao "atentado ao pudor". Em recente pesquisa realizada no Arquivo Histórico de Moçambique, Miguel (2019) identificou registros nos quais há a menção aos "vícios contra a natureza" no caso de apreensão de menores indígenas em Lourenço Marques na década de 1940. Contudo, como bem afirma o autor, "[...] a homossexualidade nunca fora o objeto central da acusação, mas apenas um adendo acusatório, uma informação que agrava e desabona moralmente os acusados por outros crimes de perturbação da ordem social, como furto, vadiagem, etc." (Miguel, 2019, p. 55).

As disposições da lei de vadiagem de 1912 só foram estendidas aos territórios africanos em 1954. Nesse ano, uma revisão do Código Penal alterou diversos artigos do Código Penal de 1852, para suprimir algumas disposições sobrepostas e adaptar o código à abordagem autoritária do Estado Novo, incluindo especialmente as medidas de segurança. As medidas de segurança permitiam ao Estado prender qualquer pessoa sem uma acusação ou julgamento formal por até 24 anos, além de suprimir temporária ou permanente os direitos políticos e remover funcionários públicos. Essas medidas foram amplamente utilizadas pela polícia política ( $\mathrm{PIDE}^{2}$ ) para reprimir opositores políticos. E elas também foram usados para reprimir a homossexualidade.

2 Polícia Internacional e de Defesa do Estado. 
Mas por que a previsão legal punitiva do "vício contra a natureza" só foi estendida às colônias portuguesas apenas nos anos 1950? Aparentemente, as sexualidades do mesmo sexo eram, de acordo com a leitura dos acadêmicos portugueses engajados na scientia sexualis, um "problema" particularmente urbano e "civilizado/ europeu”. No final do século XIX e início do século XX, alguns juristas e médicos portugueses analisaram o comportamento homossexual entre homens e mulheres. Seus trabalhos baseavam-se nos estudos europeus sobre o comportamento homossexual de Richard von Krafft-Ebing e Magnus Hirschfeld. Em geral, eles apresentaram muitos exemplos de comportamento homossexual em diferentes culturas, classes sociais e tempos. No entanto, todos enfatizavam que o comportamento homossexual era mais frequente nas áreas urbanas, bem como nas classes média e alta escolarizadas. Asdrúbral Aguiar (1926) afirmava que os homossexuais tendiam a se concentrar em centros urbanos populosos e sugeriu a existência de uma subcultura lésbica e gay relativamente bem desenvolvida de bares, bailes, bordéis, quartos alugados e banheiros nas grandes cidades europeias. Albano Santos (1903) defendia que "a inversão sexual tem sido observada em todas as epocas e em todo os povos [...] Parece, comtudo, que as funcções genesicas estão tanto mais dispostas a perverterem-se quanto mais o progresso e a civilisação [sic] colocam o homem fora do estado em que a natureza o creou" (Santos, 1903, p. 48). O neurologista e vencedor do Prémio Nobel António Egas Moniz avançou nesse argumento e defendia que:

[Nas] sociedades monogamas, superiores às primitivas sociedades polygamas, souberam transformar o homem no pae desvelado e cuidadoso. Mas ao lado d'esta vantagem, com o augmento do estado neuropathologico da sociedade, tem crescido a sensualidade que, impelindo as massas aos excessos e à libertinagem, tenta destruir as bases fundamentaes da sociedade d'hoje: a moralidade e o amor de família [sic] (Egas Moniz, 1902, v. 1, p. XIX).

Segundo Egas Moniz, a relação entre sensualidade e aumento do estado neuropatológico explicava por que o comportamento homossexual era mais frequente entre as classes instruídas, em que "atendendo a que as predisposições nervosas são condições favoráveis ao desenvolvimento da perversão sexual e que esta predisposição existe sobretudo nos meios mais cultos” (Egas Moniz, 1902, v. 2, p. 129). Seguindo seu raciocínio, pode-se sugerir que as sexualidades primitivas/africanas eram baseadas em instintos sexuais básicos e que o comportamento homossexual era menos provável de ser encontrado entre os povos indígenas. Adelino Silva (1895) também argumentou que as classes mais altas, apesar de serem as mais civilizadas, seriam mais propensas à inversão sexual, uma vez que os uranianos (um dos principais conceitos usados para descrever os homossexuais) seriam mais comumente encontrados quando houvesse maiores predisposições nervosas, presentes frequentemente em ambientes mais escolarizados.

Embora esses acadêmicos admitam a maior frequência de comportamento homossexual no ambiente urbano e entre indivíduos das classes altas, eles 
concentraram sua análise nos indivíduos da classe trabalhadora, especialmente aqueles envolvidos na prostituição masculina. Isso é previsível, já que as classes trabalhadoras e os indivíduos engajados na prostituição masculina tinham maior probabilidade de serem submetidos à vigilância e controle da polícia, fornecendo aos estudos sobre comportamento homossexual dados suficientes para entender as particularidades da "inversão sexual". O problema percebido da prostituição masculina poderia explicar por que aqueles envolvidos no "vício contra a natureza" foram equiparados aos "vadios" pelos legisladores portugueses. Ambos seriam, na ótica dos legisladores da época, "uma classe de criminosos altamente prejudiciais à sociedade, não só pelo seu parasitismo actual, mas ainda porque constitui uma primeira étape no caminho do crime de maior gravidade" (Diário da Câmara dos Deputados, 1912, p. 5). Neste sentido, “[...] regenerar êsse [sic] indivíduo, torná-lo apto para a vida, habilitá-lo a concorrer com o seu esforço para o bom funcionamento do organismo social, é atacar o crime numa das suas origens mais notáveis." (ibid.).

A lei de 1912 representou "inovação" ao lidar com o problema da vadiagem, em comparação com as disposições sobre ociosidade já inseridas no Código Penal de 1886. Ao invés de enviar os vadios para os territórios ultramarinos (o que representava um ônus ao Erário), a lei propunha enviá-los para instalações correcionais/laborais. O trabalho era considerado como a melhor maneira de "corrigir" aqueles vistos como uma ameaça à ordem social. Aqui é onde podemos encontrar a primeira menção de territórios ultramarinos nos debates sobre a lei de 1912. Seguindo uma tradição portuguesa que remonta ao século XV, muitos crimes eram punidos com o degredo para as colônias africanas, sendo a vadiagem um desses crimes. Os defensores da lei de 1912 enfatizaram a necessidade de evitar o envio de vadios para os territórios ultramarinos na África, uma vez que poderiam ser vistos como um "mau exemplo" para os povos indígenas, minando os esforços coloniais portugueses para forjar uma força de trabalho local saudável e eficiente.

Dessa forma, podemos inferir, a partir dos argumentos apresentados pelos acadêmicos e legisladores portugueses, que não haveria razão aparente para estender a disposição sobre "os vícios contra a natureza" da lei de 1912 para os territórios ultramarinos. A maioria da população nas colônias portuguesas era composta por indígenas ("primitivos" / "selvagens") que viviam principalmente em áreas rurais. Desde o século XV, a presença branca nos territórios portugueses era muito escassa. As duas maiores cidades (Luanda e Lourenço Marques) atingiram 100.000 habitantes apenas nas décadas de 1950 e 1960, respectivamente (Castelo, 2007). É bem provável que essas razões tenham contribuído para que as práticas sexuais do mesmo sexo não fossem criminalizadas em Moçambique (e nos demais territórios africanos) até 1954.

A única menção identificada à criminalização do "vício contra a natureza" aplicável aos indígenas de Moçambique está presente no projeto de "Código Penal para os Povos Indígenas de Moçambique”, elaborado em 1946 pelo jurista português João Gonçalves Cota. O projeto de código penal foi o resultado do trabalho da Missão Etognósica de Moçambique, solicitado pelo governador geral de Mo- 
çambique, José Tristão de Bettencourt, para organizar um código civil e penal aos indígenas baseado nas tradições e costumes locais (Pinho, 2015). Cota e sua equipe etognósica realizaram pesquisa sobre costumes e tradições nativas de diferentes grupos sociais em Moçambique e elaboraram um código criminal e um civil baseado em uma compilação do que eles compreendiam como princípios comuns e básicos da lei "nativa" (direito gentílico). Ambos os códigos nunca foram aplicados por causa da posição crítica de diversos burocratas coloniais, especialmente da do ideólogo colonial português Joaquim da Silva Cunha, opositor daquilo que ele entendia ser a "relativização do conceito de justiça aplicado às populações colonizadas" (Pereira, 2001, p. 32). Outro ferrenho opositor foi o bispo da Beira, D. Sebastião Soares de Resende, como será discutido mais adiante.

Por ora, é importante ressaltar que, na proposta de código penal de Cota, havia uma seção sobre vadiagem (Capítulo VI, Artigos 108 e 109) que, em grande medida, "copiava" as disposições da lei da vadiagem metropolitana de 1912. No entanto, quando se tratava do "vício contra a natureza", havia uma diferença importante: a proposta de Cota considerava apenas criminosos aqueles indígenas que "se entregavam à prática do vício contra a natureza com fins lucrativos". Para entender as razões de Cota por trás dos artigos propostos, devemos ter em mente os preconceitos raciais que informaram a compreensão dos "usos e costumes" dos povos indígenas. Parece provável que o "problema" do vício contra a natureza fosse, para Cota, algo não aplicável aos povos indígenas. Seguindo as reflexões dos autores da scientia sexualis portuguesa, a sexualidade africana estaria próxima da dos animais, impulsionada principalmente por instintos sexuais não refinados. Isso significava que, provavelmente para Cota, a sexualidade africana era basicamente heterossexual. Dessa forma, para ele, a única maneira concebível de um indígena engajar-se sistematicamente na prática do "vício contra a natureza" seria com vistas a ganhos materiais.

Nesse sentido, Cota e sua equipe não estavam particularmente preocupados em reprimir relações sexuais entre pessoas do mesmo sexo entre populações indígenas, uma vez que seria improvável que um homem africano "pagasse por sexo" com outro africano. Aparentemente, as previsões legais visavam reprimir os indígenas que tivessem relações sexuais "contra a natureza" com um suposto parceiro europeu branco que pudesse pagar. Esse raciocínio encontra guarida em documentos recentemente identificados por Miguel (2019) em sua pesquisa no Arquivo Histórico de Moçambique. Em um caso de apreensão de um jovem indígena por furto em 1945, ele relata em interrogatório que "[...] quando não tem serviço, [...] à noite entrega-se à prática de actos de sodomia com indivíduos de raça europeia, a trôco de alguns escudos que os mesmos lhe dão.” (Miguel, 2019, p. 59).

Assim, é bem provável que o objetivo de Cota em incluir a previsão sobre o "vício contra a natureza" no código penal indígena estivesse imbuído de preocupações de natureza higienista (Miguel, 2019) que visavam garantir a ordem social em um contexto de crescente urbanização das populações nativas em Moçambique.

O artigo específico sobre "o vício contra a natureza" no código proposto por Cota, assim como os casos identificados por Miguel (2019), nos dão uma visão 
importante sobre a regulação das relações entre pessoas do mesmo sexo na África colonial portuguesa: esta não foi dirigida a reprimir relações sexuais entre pessoas nativas, mas a controlar a (homos)sexualidade europeia branca e masculina. Isto provavelmente explica por que a provisão que criminaliza a prática do vício contra a natureza só foi absorvida pelo Código Penal Português de 1886 (e consequentemente expandida para o ultramar) em 1954. A partir de 1940, a administração autoritária salazarista transformou a colonização dos territórios africanos portugueses em uma prioridade. Projetos de desenvolvimento financiados pelo Estado foram implementados para tornar a colonização economicamente viável. O estado português começou a subsidiar assentamentos brancos em Angola e Moçambique, para forjar a colonização dos territórios africanos. O fim da Segunda Guerra Mundial e o surgimento de movimentos nacionalistas na África e na Ásia nos anos 1950 e 1960 levaram a ditadura de Salazar a depender cada vez mais da retórica do "império" para legitimar o regime autoritário em Portugal. Na arena internacional, o emergente antagonismo entre os blocos capitalista e socialista foi habilmente utilizado pelos funcionários do Estado Novo para garantir o apoio (ou, em muitos casos, a omissão) dos Estados Unidos e outras potências ocidentais à presença portuguesa na África (Oliveira, 2014).

Isso resultou em uma grande migração para as duas colônias, que viu um enorme aumento em sua população branca após a Segunda Guerra Mundial. Claudia Castelo (2007) apresenta estatísticas que comprovam o esforço de Portugal para colonizar as províncias ultramarinas. A população branca em Angola aumentou de 44.083 colonos no censo de 1940 para 280.101 colonos no censo de 1970. Moçambique também testemunhou um aumento constante na população branca, elevando de 27.438 colonos brancos no censo de 1940 para 162.967 colonos no censo de 1970. Provavelmente não é uma coincidência que a prostituição tenha sido criminalizada nos territórios portugueses na África e na Ásia em 1954, mesmo ano da revisão do Código Penal de 1886, que estendeu a criminalização da homossexualidade para as províncias ultramarinas. A ideologia de Estado Novo Salazarista estava fortemente comprometida com uma retórica moral católica. Nesta retórica, as sexualidades do mesmo sexo (assim como a prostituição) eram percebidas como desvios (da mesma forma que vadiagem, mendicância etc.) que deveriam ser extirpados da sociedade para garantir a harmonia social. Inclusive para garantir essa suposta harmonia, a PIDE abriu filiais em Angola e Moçambique a partir de 1954 (Oliveira, 2014).

\section{A regulação moral das sexualidades do mesmo sexo: religião e educação}

Para compreender a regulação das sexualidades do mesmo sexo na África colonial, não se deve focar apenas no Estado, mas também em outro ator importante no empreendimento colonial: a religião, particularmente as missões cristãs (Dores, 2015). Os valores morais associados à "civilização", como a frugalidade e o trabalho árduo, estavam ligados aos valores sexuais cristãos burgueses de castidade, monogamia e temperança de meados do século XIX (Tamale, 2014). A poliga- 
mia, o preço da noiva (lobolo) e alguns "ritos de passagem" sexualizados (como o wineliwa $a^{3}$ eram percebidos como características primitivas dos povos indígenas, que deveriam ser superadas com a difusão da palavra do Senhor. A educação era central para o trabalho missionário e para sua abordagem filantrópica de "esclarecimento" da população local, disseminando os supostos benefícios da civilização e progresso para as populações africanas.

No colonialismo português, a Igreja Católica (através de suas diferentes ordens religiosas) desempenhou papel central na missão civilizadora em relação aos povos indígenas no Brasil e na África a partir do século XVI. No Brasil, os jesuítas foram responsáveis por catequizar a população indígena e por educar os colonos brancos até serem expulsos dos domínios portugueses no século XVIII, voltando ao trabalho missionário na África portuguesa no final do século XIX. Nesse contexto, os jesuítas e outras ordens católicas portuguesas rivalizavam com as missões protestantes. Em algumas áreas, como na região de Tete e no sul de Moçambique, as missões protestantes estrangeiras eram mais bem financiadas e organizadas, estando em melhor posição para realizar o trabalho missionário entre a população indígena. Para garantir a sua posição no campo missionário em Moçambique, os missionários católicos reclamaram às autoridades portuguesas sobre a ameaça representada pelas missões protestantes à soberania de Portugal em África. O uso da língua portuguesa entre os povos indígenas era parte integrante da missão civilizadora na África. Consequentemente, a prática de muitos missionários protestantes de divulgar o evangelho nas línguas nativas foi percebida como uma ameaça de "desnacionalização" da população indígena (Dores, 2015).

A ascensão de Salazar ao poder na década de 1930 permitiu uma mudança radical nas relações Estado-Igreja em Portugal. A ideologia fascista e autoritária do Estado Novo foi baseada em fortes valores morais católicos, e as altas hierarquias da Igreja desempenharam um papel central no apoio ao regime (assim como na Itália e na Espanha). A Concordata de 1940 entre a Santa Sé e o Estado Português consagrou essa "parceria", dedicando a educação dos povos indígenas dos territórios ultramarinos às ordens missionárias católicas (Madeira, 2007). A chamada "educação rudimentar" (depois de 1951 denominada de "educação adaptativa") baseou-se numa versão simplificada do currículo escolar português, focada principalmente nas noções básicas de matemática, língua e história portuguesas, assim como higiene e habilidades em trabalhos manuais. Diferentemente de seus missionários protestantes, os missionários católicos compartilhavam as visões das autoridades coloniais portuguesas que colocavam o trabalho como a ferramenta mais importante para civilizar os nativos (Silva, 2015).

A educação rudimentar visava assegurar o suprimento de mão de obra nativa barata e evitar uma possível oposição ao governo português pelos indígenas. $\mathrm{O}$ Estado Novo via a educação como uma ameaça ao regime (Oliveira, 2014). Isso poderia explicar o baixo orçamento destinado à educação indígena nas últimas décadas do domínio colonial português e, consequentemente, os maus resultados nos níveis de alfabetização indígena. Em 1954, por exemplo, foram inscritos 183.092 africanos na educação rudimentar, o que representava 3,2\% da população
De acordo com Arnfred (2011), wineliwa significa rito de iniciação, na língua Emakhuwa falada pelo grupo étnico Makhuwa do Norte de Moçambique. É o rito de passagem realizado entre as mulheres $\mathrm{e}$ envolve rituais sexuais, como a simulação de relações sexuais por mulheres mais velhas e a extensão dos pequenos lábios da vagina. 
africana em Moçambique (Duffy, 1959), número significativamente baixo se comparado com outras colônias britânicas, como a Rodésia do Norte, onde, na mesma década, a taxa de matrícula escolar entre os africanos foi de 11\% (Oliveira, 2014). O ensino superior só foi estendido para as províncias ultramarinas africanas em 1968, com a fundação da Universidade de Lourenço Marques (atual Universidade Eduardo Mondlane) em Moçambique e Luanda (atual Universidade Agostino Neto) em Angola.

Os fracos resultados da educação indígena promovida por missionários católicos poderiam explicar uma influência relativamente diminuída da Igreja Católica na imposição de valores morais cristãos entre os povos indígenas. Isso pode ser demonstrado pela conservação de muitas tradições e costumes indígenas, como a poligamia, o lobolo e o wineliwa, considerados pelos padres e bispos católicos como "primitivos" e "bárbaros". Desde o século XVI, a relação entre funcionários do Estado português e missionários oscilou entre a cooperação e o conflito. No Brasil, por exemplo, os jesuítas foram os principais opositores à escravização da população indígena nos séculos XVII e XVIII, em nítido contraste com os interesses políticos e econômicos portugueses (Fausto, 1995). O mesmo parece ter acontecido também nos territórios africanos. Um bom exemplo do conflito entre autoridades coloniais portuguesas e autoridades eclesiásticas católicas em Moçambique foi a oposição proposta pelo Bispo da Beira, D. Sebastião Soares de Resende, à elaboração de códigos civis e penais baseados no "uso e costumes" indígenas (Pereira, 2001). Em um Manifesto da Diocese da Beira em 1953, o Bispo Resende e outros padres católicos se opuseram à aplicação dos dois códigos, pois reconheceriam algumas práticas nativas "imorais" e "diabólicas" como a feitiçaria, a poligamia, o pagamento do lobolo) e o nyau $^{4}$, que deveria ser reprimido pelas autoridades coloniais portuguesas (Pereira, 2001). No entanto, as práticas cotidianas dos missionários católicos em Moçambique dependiam em grande medida de um equilíbrio tênue entre impor os valores morais cristãos e aceitar algumas tradições e costumes (Pereira, 2001).

Como discutido anteriormente, a abordagem portuguesa em relação à aplicação dos "usos e costumes” em seus territórios na África foi caracterizada por algum nível de aceitação da tradição local pelas autoridades judiciais coloniais. A partir do final do século XIX, Portugal dependia em grande parte da autoridade dos régulos para assegurar uma presença fraca e limitada em África. Em muitas situações, as autoridades coloniais portuguesas "fecharam os olhos" para certas tradições indígenas, como a poligamia e o lobolo, consideradas primitivas e bárbaras, para evitar uma reação contrária das populações africanas ao domínio colonial. O objetivo principal dos oficiais coloniais portugueses era garantir o fornecimento de mão de obra nativa barata e disciplinada. Um bom exemplo dessa abordagem frouxa é relatado por Medeiros em seu estudo sobre os ritos de iniciação masculina entre Makhuas no norte de Moçambique (1995, apud Arnfred, 2014). Ele demostra que na década de 1950, devido à necessidade de mão de obra nas fazendas de algodão, os oficiais coloniais portugueses aceitavam certos rituais e tradições indígenas. Da mesma forma, missionários católicos perceberam que
4 Nyau é a denominação de um grupo secreto associado ao uso de máscaras em uma prática espiritual do povo Chewa do centro de Malawi e do oeste de Moçambique. 0 ritual foi compreendido como "obsceno" e "maligno" pelos missionários cristãos (Curran, 1999). 
tinham que entender os significados e a importância de algumas tradições dos povos indígenas, não "para eliminá-los, mas para integrá-los no contexto cristão" (Medeiros, 1995, p. 5-6, apud Arnfred, 2014, p. 169). A intensificação da luta armada entre a FRELIMO e o exército português nas décadas de 1960 e 1970 forçou a burocracia colonial a aceitar os rituais de iniciação e cerimônias indígenas como parte de uma política de conquista de “corações e mentes” em relação à população camponesa (Arnfred, 2014). Ambos os exemplos demonstram que a colonização portuguesa poderia, em algumas situações, suplantar a tarefa moral da "missão civilizatória", explicando uma abordagem relativamente "flexibilizada" se comparada às autoridades coloniais britânicas.

Quando olhamos para as práticas sexuais entre pessoas do mesmo sexo, não foram identificados registros de missionários católicos portugueses nas províncias ultramarinas africanas que mencionassem qualquer prática homoerótica entre os nativos ou mesmo qualquer caso ou polêmica implicando a Igreja Católica e suas ordens missionárias em casos de repressão da homossexualidade. A única menção às missões religiosas relacionada à homossexualidade foi identificada por Miguel (2019) no Arquivo Histórico de Moçambique. Nos casos de apreensão de indígenas por vadiagem por ele identificados na década de 1940, os agentes da burocracia colonial sugerem, como punição, que os jovens sejam enviados "para a casa dos pais, em suas terras de origem, ou serem enviados para missões religiosas para educação e correção de suas vidas na 'vadiagem”' (Miguel, 2019, p. 55), não ficando claro se os "vícios contra a natureza" seriam alvo da intervenção das instituições religiosas. Tudo parece indicar que havia um grande silêncio da Igreja Católica em relação não só à homossexualidade entre os povos africanos, mas às práticas sexuais entre pessoas do mesmo sexo de maneira mais ampla. Neste sentido, a Igreja Católica reproduziria, em grande medida, a visão pudica portuguesa em relação à sexualidade, de forma geral.

\section{Considerações finais}

As reflexões aqui apresentadas lançam luz sobre importante (e ainda pouco explorada) faceta do colonialismo português na África: o legado da regulação das relações sexuais entre pessoas do mesmo sexo nos territórios sob sua soberania. Embora os códigos penais das ex-colônias portuguesas tenham herdado a punição ao chamado "vício contra a natureza", previsão legal utilizada em Portugal continental entre 1912 e 1982 (ano de aprovação do atual código penal português) para punir práticas homoeróticas (Cascais, 2016), não foram encontradas evidências que apontam para a punição das práticas homoeróticas em si, seja entre a população africana, seja entre a população branca e/ou assimilada. Como demonstrado, a extensão para as províncias ultramarinas da criminalização do "vício contra a natureza" ocorreu apenas em 1954, mesmo ano em que a proibição da prostituição (já vigente em Portugal) é também estendida aos territórios ultramarinos. A extensão relativamente tardia da criminalização da homossexualidade nos territórios portugueses parece explicar a ausência, nas ex-colônias portuguesas na África, da 
perseguição estatal contra lésbicas e gays, tal como observada em outras ex-colônias britânicas. O cenário de maior tolerância em relação à homossexualidade em três ex-colônias portuguesas (Cabo Verde, Moçambique e São Tomé e Príncipe), se comparado com outras nações africanas ocupadas por outras potências coloniais, parece confirmar a centralidade do legado colonial para compreender as razões para a perseguição atual de cunho homofóbico no continente.

A extensão tardia da criminalização da homossexualidade aos territórios do ultramar parece estar relacionada às visões "científicas" sobre a homossexualidade elaboradas no começo do século XX, que a viam como um problema eminentemente urbano e próprio das populações "civilizadas". Nesse sentido, não haveria razão aparente para estender a disposição sobre "os vícios contra a natureza" da lei de 1912 para os territórios ultramarinos. Sob esta ótica, a maioria da população nas colônias portuguesas seria composta por indígenas "primitivos"/“selvagens" que viviam principalmente em áreas rurais; e a presença branca nos territórios portugueses era muito escassa, limitada às zonas litorâneas.

Como explorado no texto, os acadêmicos da scientia sexualis lusitana (Silva, 1895; Santos, 1903; Egas Moniz, 1902; Aguiar, 1926) vinculavam-se a noções disseminadas entre outros acadêmicos europeus de que a sexualidade africana seria "primitiva" e "instintual". Isso é reforçado quando analisamos a única iniciativa de aplicação das punições ao "vício contra a natureza" aos indígenas, proposta por Cota em 1946, que criminalizava apenas os indígenas que "se entregavam à prática do vício contra a natureza com fins lucrativos". Isso sugeriria a ideia de uma sexualidade africana basicamente heterossexual na qual, para Cota, a única forma concebível de um indígena engajar-se sistematicamente na prática do "vício contra a natureza" seria com vistas a ganhos materiais, reforçando o mito de que a homossexualidade não "existiria na África" (ou pelo menos entre os indígenas africanos).

Por fim, identificou-se que uma possível influência dos missionários vinculados à Igreja Católica na regulação das relações de gênero e sexualidade pode ter sido minimizada, dada a três razões inter-relacionadas: a) a invisibilidade da homossexualidade entre os missionários católicos, resultante do moralismo católico extremo em relação às práticas sexuais não heterossexuais; b) a fragilidade (organizacional e de recursos humanos e financeiros) em expandir seu trabalho de doutrinação moral entre a população indígena, se comparada com os missionários protestantes em outras colônias africanas (particularmente as britânicas); e c) a necessidade de "fechar os olhos" para certas práticas nativas, vistas como primitivas e bárbaras, de forma a evitar uma reação contrária das populações africanas, tanto ao trabalho missionário quanto ao domínio colonial.

Neste sentido, a relativa tolerância em relação à homossexualidade em Moçambique contemporaneamente pode ser creditada, em certa medida, ao legado de relativo "desinteresse" por parte do poder colonial português em relação às práticas sexuais entre pessoas do mesmo sexo. Como demonstrado ao longo do texto, esse desinteresse estava calcado em percepções racistas em relação às sexualidades africanas, vistas como "primitivas" e, assim, eminentemente heterossexuais, 
juntamente com forte moralismo católico que silencia e invisibiliza a sexualidade (e, particularmente a homossexualidade), vista como tabu.

Ao olharmos para a situação dos direitos LGBT na África contemporânea, o impacto do legado colonial é central para compreendermos as diferenças nos níveis de tolerância local da homossexualidade e a forma como agentes estatais têm lidado com o tema. Dois exemplos recentes demonstram isso. Em outubro de 2018, o prefeito de Dar es Salaam, maior cidade da Tanzânia, Paul Makonda, lançou uma "caçada" contra a população homossexual local, com o respaldo legal da legislação antissodomia herdada do período de ocupação britânica, gerando várias críticas da comunidade internacional (BBC News, 2018). Já Angola, em janeiro de 2019, aprovou o novo código penal que excluiu os artigos 70 e 71 relacionados aos "vícios contra a natureza", descriminalizando as práticas sexuais entre pessoas do mesmo sexo (DW, 2019).

O legado colonial é uma variável relevante para compreender os distintos níveis de homofobia estatal entre as nações africanas colonizadas por diferentes potências coloniais. Contudo, o alcance desse legado tem limites claros. No caso dos países africanos lusófonos, embora todos tenham descriminalizado a homossexualidade, isso não significa necessariamente a existência de uma postura de promoção dos direitos da população LGBT. No caso angolano, a descriminalização da homossexualidade no novo Código Penal de 2019 veio acompanhada da proibição da discriminação baseada na "orientação sexual" (DW, 2019) e do reconhecimento estatal da Associação Íris, primeira organização de defesa dos direitos da população LGBT no país (DW, 2018). No caso moçambicano, a mesma proposta de proibição da discriminação por razões de orientação sexual foi rejeitada quando da promulgação do novo Código Penal de 2015, que descriminalizou a homossexualidade. E embora a Lei do Trabalho de 2007 proíba a discriminação por orientação sexual, a Lambda, mais antiga Associação de defesa da população LGBT do país ainda luta para obter o reconhecimento legal por parte do Estado moçambicano (Miguel, 2019). Dessa forma, a compreensão das diferentes trajetórias de promoção da igualdade de orientação sexual e identidade de gênero exige análises dos processos de libertação nacional, de construções dos Estados pós-coloniais e do impacto dos atores transnacionais na politização das sexualidades dissidentes da norma heterossexual em contexto africano. 


\section{Referências}

ABSHIRE, David; SAMUELS, Michael. Portuguese Africa: a handbook. London: Pall Mall Press, 1969.

AGUIAR, Asdrúbal António de. Evolução da pederastia e do lesbismo na Europa: contribuição para o estudo da inversão sexual. Arquivo da Universidade de Lisboa, v. XI, p. 335-620.

ARNFRED, Signe. Sexuality and gender in Mozambique. Rochester: James Currey, 2011.

BASTOS, Susana. O Estado Novo e os seus vadios. Contribuição para o estudo das identidades marginais e da sua repressão. Lisboa: Dom Quixote, 1997.

BBC NEWS, Tanzania: Anti-gay crackdown in Dar es Salaam. $31^{\text {st }}$ Oct. 2018. Disponível em: https://www.bbc.com/news/world-africa-46048804. Acesso em: 26 ago. 2020.

BBC NEWS. Uganda court annuls anti-homosexuality law. $1^{\text {st }}$ August 2014. Disponível em: https://www.bbc.com/news/world-africa-28605400. Acesso em: 26 ago. 2020.

CASCAIS, António Fernando. A homossexualidade nas malhas da lei no Portugal dos séculos XIX e XX. International Journal of Iberian Studies, 29 (2) pp. 95-112. 2016.

CASTELO, Cláudia. Passagens para África: povoamento de Angola e Moçambique com naturais da Metrópole. Porto: Edições Afrontamento, 2007.

COTA, João Gonçalves. Mitologia e Direito Consuetudinário dos Indígenas de Moçambique: estudo de Etnologia mandado elaborar pelo Governo Geral da Colónia de Moçambique. Lourenço Marques: Imprensa Nacional de Moçambique, 1944.

COTA, João Gonçalves. Projeto Definitivo do Código Penal dos indígenas da Colónia de Moçambique, acompanhado de um relatório e de um estudo sobre direito criminal indígena. Lourenço Marques: Imprensa Nacional de Moçambique, 1946.

CURRAN, Douglas. Nyau Masks and Ritual. African Arts, n. 32, n. 3, p. 68-77, Autumn 1999.

DIÁRIO DA CÂMARA DOS DEPUTADOS. Sessão nº 128, 5 de junho de 1912.

DORES, Hugo Gonçalves. A missão da república: política, religião e o império colonial português. Lisboa: Edições 70, 2015.

DUFFY, James. Portuguese Africa. Cambridge: Harvard University Press, 1959.

DULANI, Boniface; SAMBO, Gift; DIONNE, Kim Yi. Good neighbours? Africans express high levels of tolerance for many, but not for all. Afrobarometer Dispatch, v. 74, n. 1, Mar. 2016. Disponível em http://afrobarometer.org/sites/default/files/publications/ Dispatches/ab_r6_dispatchno74_tolerance_in_africa_eng1.pdf. Acesso em: 26 ago. 2020.

DW. Primeira associação LGBT em Angola espera mudanças. 6 ago. 2018. Disponível em: https://www.dw.com/pt-002/primeira-associa\%C3\%A7\%C3\%A3o-lgbt-em-angola-espera-mudan\%C3\%A7as/a-44964234. Acesso em: 26 ago. 2020.

DW. Angola no pelotão da frente contra a discriminação homossexual. 12 fev. 2019. Disponível em: https://www.dw.com/pt-002/angola-no-pelot\%C3\%A3o-da-frente-contra-discrimina\%C3\%A7\%C3\%A3o-homossexual/a-47474873. Acesso em: 26 ago. 2020.

EGAS MONIZ, António. A vida sexual: Physiologia (volume I) e pathologia (volume II). Coimbra: França Amador Editor, 1902. 
EPPRECHT, Mark. Homosexual Tropes and LGBTI Strategies of Visibility South Africa and the dream of love to come: Queer sexuality and the struggle for freedom. The Journal of African History, v. 54, n. 2), p. 298-300, 2013.

FAUSTO, Boris. História do Brasil. São Paulo: EDUSP, 1995.

FIGARI, Carlos. Eróticas de la disidencia en América Latina. Brasil, siglos XVII al XX. Buenos Aires: Clacso - Ciccus, 2009.

HUMAN RIGHTS WATCH. The Alien Legacy: The Origins of 'Sodomy' Laws in British Colonialism. New York: Human Rights Watch, 2008.

ILGA- World; Lucas Ramon Mendos. State-Sponsored Homophobia 2019: Global Legislation Overview Update. Geneva: ILGA, 2019.

LENNOX, Corinne; WAITES, Matthew. Direitos humanos, orientação sexual e identidade de gênero na Commonwealth: da história e do Direito ao desenvolvimento de diálogos e ativismos transnacionais. Estudos de Sociologia, Recife, v. 2, n. 22, p. 21-117, 2016.

MACAGNO, Lorenzo. A Invenção do Assimilado - Paradoxos do Colonialismo em Moçambique. Lisboa: Colibri, 2019.

MADEIRA, Ana Isabel. Ler, escrever e orar: uma análise histórica e comparada dos discursos sobre a educação, o ensino e a escola em Moçambique (1850-1950). Tese (Doutorado em Ciências da Educação) - Universidade de Lisboa, Lisboa, 2007.

MCCLINTOCK, Anne. Couro Imperial: raça, gênero e sexualidade no embate colonial. Campinas: Editora da Unicamp, 2010.

MIGUEL, Francisco. "Levam má bô": (homo)sexualidades entre os sampadjudus da Ilha de São Vicente de Cabo Verde. Dissertação (Mestrado em Antropologia Social) -Universidade de Brasília, Brasília, 2014.

MIGUEL, Francisco. Maríyarapáxjis: Silêncio, exogenia e tolerância nos processos de institucionalização das homossexualidades masculinas no sul de Moçambique. Tese (Doutorado em Antropologia Social) - Universidade de Brasília, Brasilia, 2019.

MOTT, Luiz. Raízes históricas da homossexualidade no Atlântico Lusófono negro. Afro-Ásia, n. 33, p. 9-33, 2005.

MURRAY, Stephen O.; ROSCOE, William. Boy-wives and female-husbands: Studies in African-American homosexualities. London: Palgrave MacMillan, 2001.

NEWITT, Malyn. Portugal in Africa: the last hundred years. London: C. Hurst \& Co., 1981.

OLIVEIRA, Pedro Aires. O ciclo africano (Parte IV). In: OLIVEIRA E COSTA, João Paulo (Coord.). História da Expansão e do Império Português. Lisboa: Esfera dos Livros, 2014.

PEREIRA, Rui Mateus. A “Missão etognósica de Moçambique”. A codificação dos "usos e costumes indígenas" no direito colonial português. Notas de Investigação. Cadernos de Estudos Africanos (online), n. 1, 2001. Disponível em: https://journals.openedition. org/cea/1628. Acesso em: 26 ago. 2020.

PHILLIPS, Oliver. Blackmail in Zimbabwe: Troubling narratives of sexuality and human rights. The International Journal of Human Rights, v. 13, n. 2-3, p. 345-364, 2009.

PINHO, Osmundo. O “Destino das Mulheres e de sua Carne”: regulação de gênero e o Estado em Moçambique. Cadernos Pagu, n. 45, jul.-dez. 2015, p. 157-179. Disponível em: https://doi.org/10.1590/18094449201500450157. Acesso em: 26 ago. 2020.

SANTOS, Albano Pereira dos. Perversão Sexual. Tese Inaugural - Escola Médico-Cirúrgica do Porto, Porto, 1903. 
SERRA, Carlos. Estado, pluralismo jurídico e recursos naturais recursos naturais. 2010.

Disponível em: https://www.academia.edu/4510355/Trabalho_Pluralismo_JuridiCo_1_Carlos Serra. Acesso em: 26 ago. 2020.

SILVA, Adelino Pereira da. A Inversão Sexual: Estudos Médico-Sociais. Dissertação Inaugural - Escola Médico-Cirúrgica do Porto, Porto, 1895.

SILVA, Giselda Brito. A Educação Colonial do Império Português em África (1850-1950). Cadernos do Tempo Presente, n. 21, set.-out. 2015, p. 67-68.

SMITH, David. Nova lei não mudará o modo de viver de gays em Moçambique, diz ativista. Tradução de Paulo Migliacci. Folha de S. Paulo, 02/07/2015.

TAMALE, Sylvia. Exploring the contours of African sexualities: Religion, law and power. African Human Rights Law Journal, v. 14, n. 1, p. 150-177, 2014.

VAINFAS, Ronaldo. Trópicos do Pecado: moral, sexualidade e Inquisição no Brasil. Rio de Janeiro: Civilização Brasileira, 2010.

ZAMPARONI, Valdemir. De escravo a cozinheiro: colonialismo e racismo em Moçambique. Salvador: EDUFBA, 2012. 